\title{
Patients’ Loyalty Improvement in Public Hospital
}

\author{
M. Dachyar", Farizal, and Ika Prisila Minar \\ Industrial Engineering Department, Universitas Indonesia
}

\begin{abstract}
The purpose of this research is to improve outpatient loyalty in using National Health Insurance in a public hospital. Structural Equation Modeling (SEM) method is used to analyze factors that influence patient loyalty. The discriminant analysis method is used to know the priority for improvement. An assessment of 5 experts was performed to obtain latent variables and indicators. The questionnaire was given to 400 patients. The SEM model is concluded, satisfaction and trust are two strong factors that affect the loyalty of patients.
\end{abstract}

\section{Introduction}

The increasing number of the Indonesian population, with a $1.19 \%$ growth rate, indicates that the need for health and health facilities will also increase. However, the condition of health services, especially in public state hospitals, is still disappointing. The needs for proper healthcare are seen as potentially beneficial to private hospitals. Moreover, the implementation of National Health Insurance since 2014 is considered as a high volume business and very promising for private hospitals. It can be seen from the number of private hospitals that cover National Health Insurance continues to increase. Private hospitals in the future are predicted to be able to control $67 \%$ ownership of clinics and specialized hospital's non-maternity, laboratory clinics and check-up clinics [1]. The entry of the private sector in the hospital industry has become a matter of concern. If this continues, it is possible that the public state hospital will lose their patients.

The patient's demand for health services is getting higher, not only wanting their illness to be cured, but also wanting an excellent overall service. Public hospital as a hospital managed by the government should also improve itself in improving the quality of service to be able to satisfy the needs and expectations of patients. These improvements aim to be able to retain patients of public hospitals and acquire new potential patients. The purpose of this research is to improve outpatient loyalty in public hospital that using National Health Insurance.

\section{Literature Review}

Service quality is defined as a post-consumption evaluation comparing expectations with performance perceptions $[2,3,4]$. Measurement of service quality in public hospitals has a positive impact on patients, such as short patient waiting times, decreased hospital infections,

* Corresponding author: mdachyar@yahoo.com 
decreased medical errors [5]. Perceived value is defined as a tradeoff between the quality or benefits gained in a product or service against the sacrifice provided by paying for the product or service $[6,7]$. In a public hospital, perceived value is the patient's perception of the difference or incompatibility between total benefit and total sacrifice. Therefore, if the total sacrifice is higher, the perceived value of hospital services will be low, whereas small sacrifices with high benefits will lead to high patient satisfaction [8].

Trust represents the reliability, integrity, intensity, and attitude of the hospital felt by the patient $[9,10]$. Trust becomes one of the factors affecting patient loyalty to hospitals $[10,11$, 8]. Patient satisfaction is considered increasingly important and seen as a vital component of hospital services [12]. Patient satisfaction will lead to patient loyalty [13], as patients tend to re-visit [14] and give word-of-mouth [15]. In addition, patient satisfaction will also enhance the reputation and image of the hospital [14].

There are four types of behaviors that indicate customer loyalty [16], i.e. making a regular repetitive purchase, buying inter-product lines and services, referring to others, and cannot be influenced by competitors to move. Loyalty represents the trustworthiness of the customers [17]. On the other hand, disloyal patients will very easily move to other health services and spread the negative news to others [18].

\subsection{Structural Equation Modeling (SEM)}

Structural Equation Modeling (SEM) is a multivariate analysis approach used to test and estimate the causal relationship between variables, even when the relationship is hypothetical or not directly observable. SEM is considered to have advantages over other methods, such as multiple regression [19]. The SEM method consists of five main stages [20], namely the stages of specification, identification, estimation, model test, and re-specification.

\section{Research Methodology}

\subsection{Development of Initial Research Model}

At the specification stage, a literature study was conducted to find out the latent variables that influence patient loyalty and its indicators. Then, latent variables and indicators are assessed by five experts. From the results of the assessment of five experts who then averaged using the geometric mean, four latent variables affecting loyalty were obtained, which are service quality, perceived value, satisfaction, and trust.

From the results of the expert assessment, there are eight initial hypothesizes to be tested in this research, namely:

H1: Service quality affects the perceived value

H2: Quality of service affects the patient's trust

H3: Quality of service affects patient satisfaction

H4: Service quality affects patient loyalty

H5: Perceived value affects patient satisfaction

H6: Patient confidence affects patient satisfaction

H7: Patient confidence affects patient loyalty

H8: Patient satisfaction affects patient's trust

H9: Patient satisfaction affects patient loyalty

Then, indicators of each latent variable, 18 indicators for service quality, 4 indicators for trust, 3 indicators for patient satisfaction, 5 indicators for patient loyalty were obtained based on the expert's assessment. 


\subsection{Development of Questionnaire}

The questionnaire used in this study is divided into two main parts, wherein the first part is a question related to the identity of the patient and the second part is statements that state the level of agreement on the latent variables. The questionnaire consisted of 32 indicator variables. A 5-point Likert scale was used to measure the level of respondent's approval of questions related to the latent variables used in the study, ranging from strongly disagree to strongly agree. A pilot test was carried out to 40 patients to check the validity and reliability of the questionnaire and to ensure that the use of words and sentences in the questionnaire was accurate and easy to understand.

\subsection{Sample and Data Collection}

The population of this study was patients from Pasar Rebo Public State Hospital located in Jakarta. Samples from this study were outpatients using BPJS and had visited the same doctor at least three times. Patient selection is done randomly. To be able to meet the adequacy of data, at least five times from the number of indicators, which is 150 respondents, conducted data collection to 400 patients. Respondents consisted of 295 women (74\%) and 105 men $(26 \%)$.

\section{Results and Discussion}

\subsection{Measurement Model}

Previously, measurements of the degree of freedom and normality of data were performed. A total of 32 questions used (variables studied) were divided into five latent variables, each latent variable has a good level of validity with a standard loading factor that ranges from 0.539 to 0.832 and a good level of reliability with CR that ranges from 0.79 to 0.94 . A construct model has good reliability if its construct reliability (CR) is more than 0.7 and its variance extracted (VE) value is more than 0.5 .

\subsection{Structural Model}

Previous research recommends reporting some model fit indicators, which represent at least three categories, absolute fit, model comparison, and parsimonious fit [20]. The goodness of fit test that is considered in absolute fit indices is Root Mean Square Error Approximation (RMSEA) and Standardized Root Mean Square Residual (SRMSR). The Incremental fit measure can be estimated from the NFI (Normed Fit Index) and CFI (Comparative Fit Index) The parameters that can be used for parsimonious are CFI and RMSEA. The results of the model goodness of fit test and the standard of each parameter [21] is acceptable structural model that can be seen in Table 1 .

Table 1. The goodness of Fit Indices of Model

\begin{tabular}{|l|l|l|l|}
\hline GOF Criteria & Fit Criteria & \multicolumn{2}{|l|}{ Result } \\
\hline RMSEA & $<0.08$ & 0.070 & Fit \\
\hline SRMR & $<0.08$ & 0.015 & Fit \\
\hline CFI & $>0.90$ & 0.901 & Fit \\
\hline NFI & $>0.80$ & 0.857 & Fit \\
\hline CMIN/DF & $<3$ & 2.928 & Fit \\
\hline
\end{tabular}




\subsection{Causal Relationship}

Once an acceptable structural model is formed, it is necessary to evaluate the statistical significance of SEM. By looking at the value of the p-value of the regression weight calculation, it can be seen whether the relationship between latent variables is significant or not, between exogenous variables and endogenous variables. If $p$-value $<0.05$, it can be said there is a significant relationship between latent variables. In Table 2., the results show the calculation of the model regression weight.

Table 2. Summary of Hypothesis Testing Results

\begin{tabular}{|lll|c|c|c|}
\hline & & & $\begin{array}{c}\text { Standardized } \\
\text { Regression Weight }\end{array}$ & $\mathrm{P}$ & \\
\hline Perceived Value & $\leftarrow$ & Service Quality & 0.751 & $* * *$ & Significant \\
\hline Trust & $\leftarrow$ & Service Quality & 0.111 & 0.309 & Not Significant \\
\hline Satisfaction & $\leftarrow$ & Perceived Value & 0.696 & $* * *$ & Significant \\
\hline Satisfaction & $\leftarrow$ & Service Quality & 0.524 & $* * *$ & Significant \\
\hline Loyalty & $\leftarrow$ & Trust & 0.403 & $* * *$ & Significant \\
\hline Loyalty & $\leftarrow$ & Satisfaction & 0.599 & $* * *$ & Significant \\
\hline Loyalty & $\leftarrow$ & Service Quality & -0.053 & 0.502 & Not Significant \\
\hline Satisfaction & $\leftarrow$ & Trust & -0.185 & 0.337 & Not Significant \\
\hline Trust & $\leftarrow$ & Satisfaction & 0.835 & $* * *$ & Significant \\
\hline
\end{tabular}

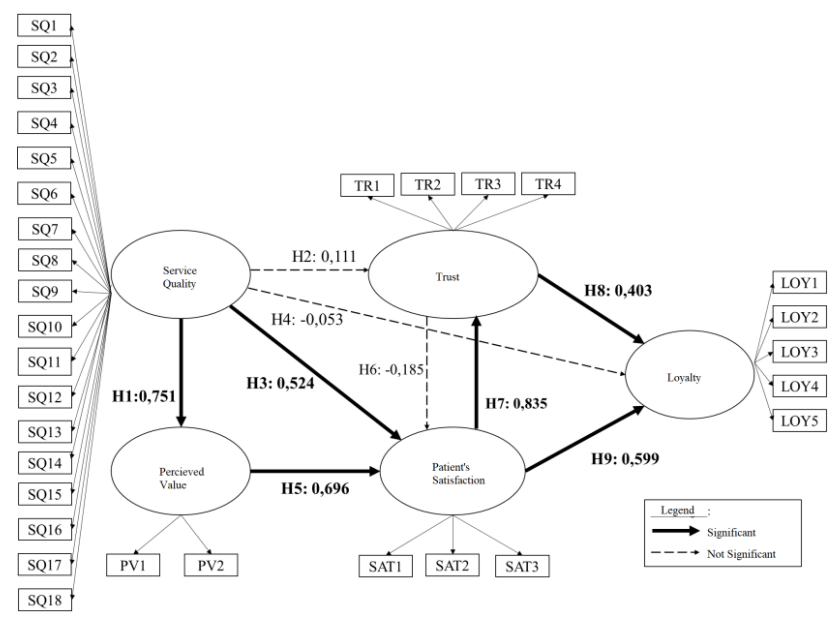

Fig. 1. The Estimated Structural Model

From the calculation above, it is known that the $\rho$-value marked with three stars is significant because $\rho$-value is less than 0.001 or in other words to the strong relationship between the two variables and the hypothesis accepted. Loyalty model can be seen in Fig. 1. Out of the 9 hypothesizes testing conducted, it is known that 6 hypothesizes are accepted on the model. Service quality and percieved value greatly affect patiens' satisfaction. patients' satisfaction greatly affects trust. Trust and patients' satisfaction greatly affect loyalty of patients.

Based on Fig. 1, it can be seen that satisfaction and trust are factors that have a direct relationship to patient loyalty in hospitals. Satisfaction does have a greater impact on loyalty than trust. Satisfaction becomes the factor that connects service quality [22] and perceived value [8] to loyalty. To improve satisfaction, the public hospital needs to improve the indicator of perceived value, trust, and quality service. 


\section{Conclusion}

This research obtained 5 latent variables and 32 indicator variables in patient loyalty model in public hospital. Factors that have the most important effect on patient loyalty is the service quality. Satisfaction and trust are two strong factors that affect the loyalty of patients. To gain the patient's trust, management can focus on several factors such as reliability, integrity, intensity, and attitude of doctors. To improve patient satisfaction, the public hospital needs to improve their effort in perceived value, trust, and quality service.

This research funded by Universitas Indonesia - PITTA 2017

\section{References}

1. Ernst \&Young, (2015).

2. Parasuraman, V. A. Zeithaml, and L. L. Berry, J. of Mkt. 49, 41-50 (1985).

3. M. Dachyar and L. Hananto, Mgmt. and Tech. K., Svc., T. \& Hosp. (2014).

4. Grönroos, Int. J. of Ops \& Prod. Mgmt., 9-19 (1988).

5. S.-J. Yoon, D.-C. Choi and J.-W. Park, The Svc. Ind. J., 371-388 (2007).

6. V. A. Zeithaml, L. L. Berry, and A. Parasuraman, J. of Mkt, 35-48 (1988).

7. K. B. Monroe, Making Profitable Decisions (1990).

8. M. A. Moliner, J. of Sci. Mgmt., 76-97 (2009).

9. M. J. Sanchez-Franco, A. F. V. Ramos and F. A. M. Velicia, Info. \& Mgmt, 196-202 (2009).

10. R. M. Morgan and S. D. Hunt, J. of Mkt., 20-38 (1994).

11. J. Singh and D. Sirdeshmukh, J. of the Ac. of Mkt. Sci., 150-167 (2000).

12. R. N. Jandavath and A. Byram, Int. J. of Pharm. and H. C. Mkt. (2016).

13. Anbori, S. N. Ghani, H. Yadav, A. M. Daher and T. T. Su, Int. J. for Q. in H. C., 310315 (2010).

14. S. M. Lee, D. Lee, and C.-Y. Kang, The Svc. Ind. J., 17-36 (2012).

15. R. E. Herzlinger, Harvard Business Review, 57 (2006).

16. D. L. Stum and A. Thiry, T. \& Dev. J., 34-36 (1991).

17. M. Dachyar and Fatkhurrohman, W. Ac. of Sci., Engr. and Tech., 845 - 849 (2011).

18. C.-W. Chang, T.-H. Tseng and A. G. Woodside, J. of Svcs. Mkt., 91-103 (2013).

19. C. B. Astrachan, V. K. Patel, and G. Wanzenried, J. of F. Bus. Str., 116-128 (2014).

20. M. S. Khine, Application of Structural Equation Modeling in Educational Research and Practice (2013).

21. D. Hooper, J. Coughlan, and M. Mullen, The Elect. J. of Bus. Res. Mtd, 53-60 (2009).

22. M. G. Mbuthia and E. Thaddaeus, Op. Acc. Lib. J. 2 (2015). 